\title{
Inferior mesenteric vein pylephlebitis due to sigmoid diverticulitis
}

\author{
Cisel Yazgan, ${ }^{1}$ Meltem Akkas, ${ }^{2}$ Mehmet Mahir Ozmen ${ }^{3}$
}

${ }^{1}$ Department of Radiology, Faculty of Medicine, Hacettepe University, Ankara, Turkey ${ }^{2}$ Department of Emergency Medicine, Faculty of Medicine, Hacettepe University, Ankara, Turkey

${ }^{3}$ Department of Surgery, Faculty of Medicine, Hacettepe University, Ankara, Turkey

\section{Correspondence to} Dr Cisel Yazgan, yazgancisel@hotmail.com

Accepted 6 November 2015

\section{CrossMark}

To cite: Yazgan $C$ Akkas M, Ozmen MM. BMJ Case Rep Published online: [please include Day Month Year] doi:10.1136/bcr-2015212599

\section{DESCRIPTION}

A 55-year-old man was admitted to the emergency department, with high fever. Physical examination revealed a soft abdomen without any signs of peritoneal irritation and bowel sounds were normal. Laboratory tests revealed elevation of white cell count $\left(11.5 \times 10^{3} / \mathrm{mm}^{3}\right)$ and $\mathrm{C}$ reactive protein. Contrast-enhanced CT showed sigmoid colon diverticulosis and increasing stranding of fat tissue adjacent to the sigmoid colon, in keeping with diverticulitis (figure 1). In addition, complete thrombosis of the inferior mesenteric vein (IMV) with intraluminal filling defect, perivenous inflammatory changes and subtle enhancement of the venous wall were identified (figure 2). There was no involvement of splenic and superior mesenteric veins, and intraluminal air was not present. A Gram stain of the patient's blood revealed the presence of Gram-negative bacilli. He was discharged and followed up on antibiotics and anticoagulation therapy.

Thrombophlebitis of the inferior mesenteric vein is commonly associated with the intra-abdominal inflammatory process and is also referred to as pylephlebitis. ${ }^{1}{ }^{2}$ Sigmoid diverticulitis is the most common causative aetiology following other possible causes such as appendicitis, pelvic infections, pancreatitis and inflammatory bowel disease. The mortality rate is high in cases complicated by hepatic abscess or bowel ischaemia and infarction. ${ }^{3}$ Owing to its nonspecific signs and symptoms such as fever and nausea, imaging findings of IMV thrombophlebitis are very essential in its accurate diagnosis. CT is the diagnostic tool, with its high sensitivity in displaying intraluminal filling defects

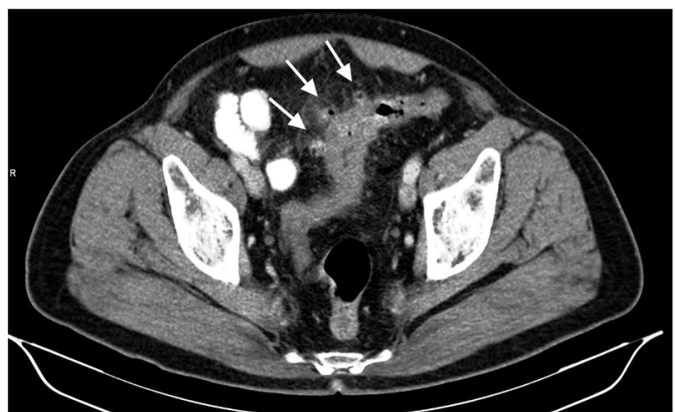

Figure 1 Contrast-enhanced axial CT image demonstrating multiple diverticula (arrows) and wall thickening of the sigmoid colon as well as surrounding fat stranding, in keeping with sigmoid diverticulitis.

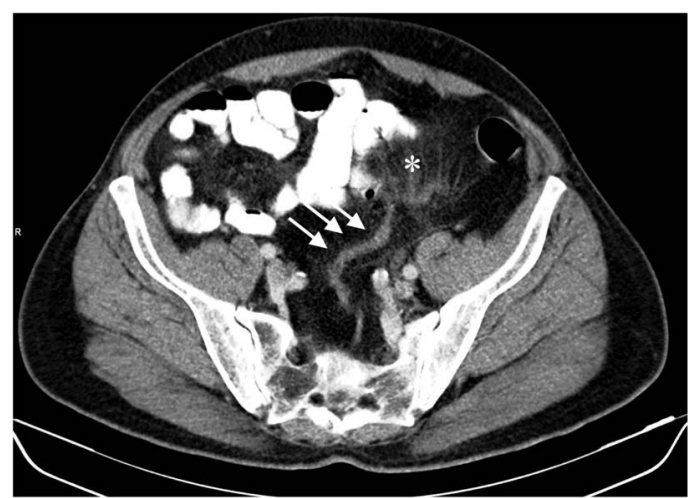

Figure 2 Contrast-enhanced axial CT image showing pylephlebitis of the inferior mesenteric vein with hypodense filling defect through the lumen of the inferior mesenteric vein (arrows) and peripheral inflammatory changes (star).

and underlying intra-abdominal inflammatory processes. Furthermore, life-threatening complications accompanied by IMV pylephlebitis can also be determined precisely by CT.

\section{Learning points}

Septic thrombophlebitis of the inferior mesenteric vein is a rare complication of the intra-abdominal inflammatory process and requires early diagnosis to prevent life-threatening complications. Radiologists must be aware of this fatal complication and assess the mesenteric venous system using contrast-enhanced CT.

Contributors $\mathrm{CY}$ reviewed the literature and wrote the manuscript. MA and MMO revised and edited the manuscript. Competing interests None declared.

Patient consent Obtained.

Provenance and peer review Not commissioned; externally pee reviewed.

\section{REFERENCES}

1 Nobili C, Uggeri F, Romano F, et al. Pylephlebitis and mesenteric thrombophlebitis in sigmoid diverticulitis: medical approach, delayed surgery. Dig Liver Dis 2007;39:1088-90.

2 Triantopoulou C, Komitopoulos N, Polyzou A, et al. Pylephlebitis associated with intrauterine device: CT evaluation. Eur I Radiol Extra 2005:55:93-6.

3 Kumar S, Sarr MG, Kamath PS. Mesenteric venous thrombosis. N Engl J Med 2001;345:1683-8. 
Copyright 2015 BMJ Publishing Group. All rights reserved. For permission to reuse any of this content visit http://group.bmj.com/group/rights-licensing/permissions.

BMJ Case Report Fellows may re-use this article for personal use and teaching without any further permission.

Become a Fellow of BMJ Case Reports today and you can:

- Submit as many cases as you like

- Enjoy fast sympathetic peer review and rapid publication of accepted articles

- Access all the published articles

- Re-use any of the published material for personal use and teaching without further permission

For information on Institutional Fellowships contact consortiasales@bmjgroup.com

Visit casereports.bmj.com for more articles like this and to become a Fellow 